\begin{tabular}{l|l} 
Investigaciones & $\begin{array}{l}\text { Revista Colombiana } \\
\text { de Educación, N. 63. } \\
\text { Segundo semestre de 2012, } \\
\text { Bogotá, Colombia. }\end{array}$
\end{tabular}

\section{Cine y educación - Campo de visión, movimiento, velocidad y poder}

\author{
//Picture theatre and education. Field of \\ view, movement, velocity and power \\ //Cinema e educação. Campo de visão, \\ movimento, velocidade e poder
}

\begin{abstract}
Este documento fue preparado como lección introductoria al seminario doctoral "Pedagogía, escuela y cine", cuya segunda versión recibió el nominativo de "Educación, subjetividad y estética: Miradas investigativas en tiempos de encrucijada" . Seminario dictado respectivamente en el primer y segundo semestre del 2011 en el Doctorado Interinstitucional en Educación, sede Universidad Pedagógica Nacional. Se inscribe también dentro de los resultados del proyecto de investigación "Modernización, subjetividad y sociedad de control en la educación en Colombia" del CIUP.

** Doctor en Filosofía y Ciencias de la Educación (Uned, España). Profesor e investigador de la Universidad Pedagógica Nacional. Miembro fundador y activo del Grupo de Historia de la Práctica Pedagógica. Sitio web: www.albertomartinezboom.com Correo electrónico: almarboom@yahoo.com

Licenciado en Filosofía y Letras (Universidad de Caldas). Estudiante de la Maestría en Educación (Universidad Pedagógica Nacional). Coinvestigador en algunos proyectos del grupo de historia de la práctica pedagógica. Correo electrónico: aulamundo@yahoo.com
\end{abstract}

\section{Resumen}

Afirmar que el cine nos ayuda a pensar y nos hace contemporáneos significa darle un lugar que resulta próximo al que estaría llamado a cumplir la filosofía. Cine, educación e investigación se articulan en este trabajo como lugares que permiten ver y crear. Inscrito al interior de la experiencia formativa de un seminario doctoral se entretejen aquí insinuaciones, preguntas y conexiones que eluden toda conclusión. Cuatro acápites ordenan analíticamente el recorrido: pensar el cine y el cine en el pensamiento, relaciones entre cine y educación, el cine como campo de visión, Blow Up y Las babas del diablo. Acápites que deliberan con una economía política de la velocidad que afecta las posibilidades y las prácticas de quienes intentan aún el pensamiento y la investigación.

\section{Abstract}

To affirm that picture theatre helps us think and makes us contemporaries means giving it a place that becomes near to what philosophy comes to do. Picture theatre, education and investigation articulate in this essay as places that allow vision and creation. Enrolled in the interior of the formative experience of a doctoral seminar are interwoven insinuations, questions and conections that elude every conclusion. Four sections order analytically the path: to think picture theatre and picture theatre in thinking, relations between picture theatre and education, picture theatre as a field of vision, Blow-Up and Las Babas del Diablo. Sections that deliberate with a political economy of velocity that affects the possibilities and the practices of whom still try thinking and investigation.

\section{Resumo}

Afirmar que o cinema nos ajuda a pensar e nos faz contemporâneos significa dar-lhe um lugar que resulta próximo ao que estaria chamada a cumprir a filosofia. Cinema, educação e investigação se articulam neste trabalho como lugares que permitem ver e criar. Inscrito no interior da experiência formativa de um seminário doutoral, aqui se entretecem insinuações, perguntas e conexões que eludem toda conclusão. Quatro pontos ordenam analiticamente o percurso realizado: pensar o cinema e o cinema no pensamento, relações entre cinema e educação, o cinema como campo de visão, Blow up e as babas do diabo. Pontos que deliberam com uma economia política da velocidade que afeta as possibilidades e as práticas daqueles que intentam ainda o pensamento e a investigação.

\section{Palabras Clave}

Campo de visión, cine, investigación, movimiento, educación, pensamiento, velocidad, poder.

\section{Keywords}

Field of view, picture theatre, investigation, movement, education, thinking, velocity, power.

\section{Palavras chave}

Campo de visão, cinema, investigação, movimento, educação, pensamento, velocidade, poder. 
Deslumbrada por tantas y maravillosas invenciones, la gente de Macondo no sabía por dónde empezar a asombrarse. Se trasnochaban contemplando las pálidas bombillas eléctricas alimentadas por la planta que llevó Aureliano Triste en el segundo viaje del tren, y a cuyo obsesionante tumtum costó tiempo y trabajo acostumbrarse. Se indignaron con las imágenes vivas que el próspero comerciante don Bruno Crespi proyectaba en el teatro con taquillas de boca de león, porque un personaje muerto y sepultado en la película, y por cuya desgracia se derramaron lágrimas de aflicción, reapareció vivo y convertido en árabe en la película siguiente. El público que pagaba dos centavos para compartir las vicisitudes de los personajes, no pudo soportar aquella burla inaudita y rompió la silletería. El alcalde, a instancias de don Bruno Crespi, explicó mediante un bando, que el cine era una máquina de ilusión que no merecía los desbordamientos pasionales del público. Ante la desalentadora explicación, muchos estimaron que habían sido víctimas de un nuevo y aparatoso asunto de gitanos, de modo que optaron por no volver al cine, considerando que ya tenían bastante con sus propias penas para llorar por fingidas desventuras de seres imaginarios (García Márquez, 2007, p. 257).

La escena de Cien años de soledad alude al cine como máquina de ilusión. Una constatación que interroga los límites y las posibilidades de aquello que creemos ver. Sabemos que los campos de visibilidad son irreductibles al lenguaje, sin embargo, es tarea de la investigación esforzarse en usar sus herramientas tanto para decir como para hacer ver. Cine e investigación coinciden en este punto: muestran lo que construyen y objetivan, no se puede hablar de lo que no muestran.

Pensamos que el cine suministra un campo de visión amplio, complejo, ancho y ajeno, si se nos permite emplear aquí la metáfora de Ciro Alegría. Agregar a lo que leemos una poética de las imágenes y en el cruce de estos lenguajes plantear relaciones inusuales, móviles, con articulaciones parciales, pero también susceptibles de ser leídas desde sus bordes. Un investigador sabría situarse al margen e intentar contemplar todos los detalles. La plena luz y la mirada captan, mucho mejor, la trampa de 
lo visible ${ }^{1}$, un adentro de cómo se investiga y un afuera de sus propias limitaciones.

Una novela, una película o un poema nos invitan, casi siempre, a mirar por las fisuras de lo que creíamos saber, cuestionan nuestras certezas, no porque muestren exactamente algo de lo que nos sucede, sino porque cobijan excesos, fragmentos, silencios, una especie de estar afuera de nosotros mismos. Esto dice Daniel Lefebvre, el director de la escuela Léo Lagrange en la película Hoy empieza todo ${ }^{2}$ de Bertrand Tavernier:

Hay cosas que nunca destruirán aquí. Están en la carne. Hablan, están en la tierra. Montones de piedras apiladas una a una. Son las manos de nuestros antepasados. Toda su paciencia acumulada. Resistieron las Iluvias, el horizonte,

1 Alusión a las posibilidades del dispositivo panóptico en Vigilar y castigar (Foucault, 1995, p. 204)

2 Título original: Ça commence aujourd'hui. País: Francia. Año: 1999. Duración: 107 minutos. Director: Bertrand Tavernier. Guión: Dominique Sampierom (que fue maestro durante más de veinte años en Hernaing, una localidad de norte de Francia), Tiffany Tavernier y Bertrand Tavernier. Fotografía: Alain Choquart. Montaje: Sophie Brunet. Vestuario: Marpessa Djian. Música: Louis Sclavis. Producción: Alain Sarde/Little Bear/TF1 Production. Intérpretes: Philippe Torreton (Daniel Lefebvre), María Pitarresi (Valéria), Nadia Kaci (Samia Damouni), Véronique Ataly (Madame Liénard), Nathalie Bécue (Cathy), Emmanuelle Bercot (Madame Tiévaux), Christine Citti (Madame Baudoin), Christina Grevillen (Sophie), Sylviane Goudal (Gloria), Betty Teboulle (señora Henry), Gérard Giroudon (Alcalde), Didier Bezace (Inspector). amontonándolas de noche para que la luz de la luna entrara en ellas. Para erguirse. Para inventar montañas y jugar al trineo. $Y$ creer que alcanzas las estrellas. Le contaremos a nuestros hijos que fue duro, pero que eran unos señores y que heredamos eso de ellos: montones de piedra y el coraje para levantarlas.

Lejos del lenguaje que satura, que intenta explicarlo todo, nos abren un resquicio, sugieren nuevas visibilidades para viejos problemas.

Edward Said pensaba que la función de los intelectuales pasa necesariamente por generar perplejidad ${ }^{3}$, es decir, multiplicar las formas de mirar, Ilamar la atención sobre las posibilidades de una mirada menos ingenua, más crítica y minuciosa. Sabemos que el trabajo intelectual pasa por ese esfuerzo del pensamiento cuando anuncia la llegada de acontecimientos capaces de mutar mucho más rápido y cuyos efectos parecen ganar en sutileza, sofisticamiento, multiplicidad y porosidad, por ejemplo: la hiperrealidad creada por la proliferación de las pantallas; la producción del deseo y de los mundos que los anticipan; los efectos de la inmersión

3 La cita completa dice: "Para lo que menos debería estar un intelectual es para contentar a su audiencia: lo realmente decisivo es suscitar perplejidad, mostrarse contrario e incluso displicente" (Said, 1996, p. 31). 
en los mundos virtuales ${ }^{4}$ sobre los cuerpos y los territorios, en fin, una velocidad abrumadora que cambia la educación, sus tiempos y sus rituales.

Tanto el cine como la investigación alteran nuestra forma de mirar. Cuesta trabajo obviar el efecto de profundidad de ambas disposiciones. Como práctica de seminario doctoral interrogamos la aspiración formativa de un especialista, de un experto, en favor de la formación de un espíritu. Entendemos por tal un investigador capaz de conmoverse con la literatura, que disfruta de la música y de la conversación, que ritualiza la comida y los viajes, que incorpora el debate político y ético de lo que pasa ante sus ojos. Jorge Larrosa lo diría así: “Un ejemplo del lugar en el que se asienta nuestra imposibilidad de ser algo y de dar sentido a lo que nos pasa" (1998, p. 65), a propósito del guión cinematográfico: Falso movimiento ${ }^{5}$ de Peter Handke (adaptación del Wilhelm Meister de Goethe y que fue dirigida por Wim Wenders). Semejante ejercicio intelectual supone el deleite, la capacidad de derroche en el acto de pensar y de leer, por eso el cine. No es posible pensar hoy sin el matiz del cine.

Nunca como ahora poder ver, lograr apropiar un campo de visión, ha devenido en asunto fundamental para poder pensar. Nietzsche había advertido en el cierre de su siglo que: "Hay hombres que en cuanto abren los ojos, manchan con la mirada" (Nietzsche, 2001, p. 101). Entre las imágenes que atraen y dominan el mundo del espectáculo y aquellas otras que no cesan de producir sensaciones, la investigación y los investigadores construyen el sesgo de lo que miran y de la forma en que han aprendido a mirar. No sorprende entonces que intentemos ese desplazamiento entre lo ambiguo de la imagen y la ambivalencia de la mirada del que habla Carlos Skliar en su diccionario de palabras ensayadas ${ }^{6}$.

4 Afirma Pierre Lévy que: "Lo virtual no se opone a lo real, sino a lo actual en cuanto a dos formas de ser diferente... Es un real fantasmagórico, latente. Lo posible es idéntico a lo real: sólo le falta la existencia" (Lévy, 1999, pp. 17-18).

5 Título original: Falsche bewegung. País: Alemania. Año: 1975. Duración: 103 minutos. Director: Wim Wenders. Guión: Meter Handke, adaptación de Años de aprendizaje de Wilhelm Meister de Johann Wolfgang Goethe. Fotografía: Robbie Müller. Montaje: Meter Przygodda. Música: Jürgen Knieper. Producción: Solaris Film y WDR. Intérpretes: Rüdiger Vogler (Wilhelm), Hanna Schygulla (Therese), Hans-Christian Blech (Laertes) Nastassia Kinski (Mignon), Peter Kern (Bernard Landau), Marianne Hope (señora Meister), Ivan Desny (industrial), Lisa Kreuzer (Janine).

6 "Por eso la pedagogía debería ser un modo de sorpresa y no una habituación; una renovación de lo sensible, de lo estético y un alerta -ético- hacia las miradas que desprecian, subestiman, humillan y denigran a los demás. Quitarse de la literalidad de la imagen, renunciar a la simplicidad de lo visto e instalarse en ese sitio tan incómodo como lo es e de la ambigüedad de la imagen y el de la ambivalencia de la mirada" (Skliar, 2011, p. 269) 
Si imaginamos que las instituciones académicas serias se miden por los seminarios que dictan, esta suerte de composición entre lenguajes, discursos y campos visuales entreteje un efecto de rareza que solo busca producir afecciones, incitaciones e incomodidades. Efecto que podríamos asociar a otras propuestas de seminarios doctorales cuyos nominativos suponen mezcla y dificultad: "Thomas Mann y el tiempo", "Cultura y gastronomía", "Cine, exilio y fascismo", "Gustav Mahler: investigar y componer", "Tres ojos: Bergman, Nietzsche y Musil", entre otros.

\section{Pensar el cine y el cine en el pensamiento}

Cuando los hermanos Lumière, en la vespertina del 28 de diciembre de 1895, comenzaron a congregar una multitud de curiosos para que contemplaran, expuestas sobre un telón, las primeras imágenes de unos obreros saliendo de la fábrica salidas de su cinematógrafo, no imaginaron que con el correr de los años ese experimento iba a convertirse en un lenguaje sofisticado y en una herramienta capaz de movilizar el pensamiento.

Aquel arte novísimo, expuesto por primera vez en el Gran Café de París, parecía dirigirse casi exclusivamente al divertimento popular, sin embargo, su impacto sensorial y psicológico, además de su frontalidad y autarquía, expandieron sus posibilidades. Del lugar de la curiosidad científica se pasó rápidamente a formas cada vez más específicas de exploración del mundo. La contundencia de la imagen en movimiento impactó el ánimo de espectadores y realizadores, y su perfeccionamiento posterior, en términos de sonorización, color y variedad narrativa, dio lugar a un espectáculo de masas que es al tiempo industria, arte y medio capaz de formar opinión pública.

El cine se ha convertido entre nosotros en registro de época. Registro que es también lenguaje, es decir, una herramienta para pensar. La reflexibilidad del cine exige cada vez más un espectador capaz de asumir disposiciones activas. Mirar el cine como recurso que facilita, como estrategia que media, como herramienta de uso didáctico nos resulta un triste papel, un servicio reductor. Ya advertía Walter Benjamin sobre esa sensibilidad para lo igual en el mundo caracterizada por poner en sintonía la realidad con la masa y viceversa.

El buen cine ${ }^{7}$ nos hace pensar. Se trataría entonces de abordar el cine como aquello que nos hace pensar y que es diferente del buen pensar. Pensar sería traducible aquí a pro-

\footnotetext{
Más que una distinción maniquea aludimos aquí a un problema estético, el buen cine alude al cine culto y no al cine destinado al espectáculo: "La gran paradoja del cine espectáculo contemporáneo, apoyado en los trabajos de creación mediante cuerpos artificiales, paisaje cibernéticos, luces sintéticas y efectos apabullantes, reside en que a pesar del éxito comercial sus propuestas en muchos casos ponen en evidencia un claro fracaso estético" (Quintana, 2011, p. 115).
} 
blematizar, interrogar, historizar aquello que aparece como verdadero y lograr develar que tiene relaciones con el poder, aún más, es el poder el que lo enuncia como verdad. Esa traducción del cine como pensamiento constituiría también su papel en cuanto posibilidad crítica. La vieja pregunta que Heidegger abordó como libro muta aquí a una acción que incomoda, desacomoda y no es confortable. Mucho más cuando advertimos que el suyo es un lenguaje cifrado cuyo dominio y control está en manos restringidas.

El cine se mueve entre la imagen y la realidad, su campo de visión no es natural, sino suministrado, supone una construcción, es decir, tiene su propia gramática. Ángel Quintana decía en ese libro dedicado a pensar la imagen y la realidad en la era digital que:

El factor clave no consiste en la búsqueda de una quimérica verdad de las imágenes como síntesis de una verdad del mundo, sino en ver cómo el cine nos remite al estatuto de cierto arte contemporáneo cuya principal preocupación ya no consiste en mostrar la distancia entre la imagen/signo y el mundo/referente, sino en crear imágenes que sean capaces de invocar lo que Jacques Rancière ha definido como la pérdida del mundo o la caída de los lazos sociales que unían las imágenes en un destino común (Quintana, 2011, pp. 137-138).

La imagen es hoy un espacio abierto, la imagen digital ha roto toda noción de frontera.

Tenemos por supuesto múltiples opciones, algunas de ellas antinómicas, otras paradójicas entre sí y que nos incitan a la reflexión, mencionemos algunas: leer estos fenómenos como pérdida del mundo y de nosotros mismos; aceptar el avasallamiento de lo que va muy rápido; añorar los esquemas figurativos de composición; rehabilitar el encanto de pequeños formatos más adecuados al arte del archivo y de la escritura; relativizar la función de las percepciones visuales; en todo caso, el resultado de esta ductilidad no es ya un tema de ciencia ficción, sino de inmaterialidad e indefinición del campo de visión que el cine suministra, es decir, nuevas escrituras audiovisuales, otras temporalidades, redimensión del realismo y de su propia velocidad.

En este sentido, el cine como dispositivo no solo deja ver, sino que también trabaja con la velocidad, o mejor, como está provisto de velocidad es susceptible de entrar en forcejeo con 
otras velocidades. No es exagerado ver en el cine un modo de afirmación y resistencia frente a aquellos movimientos ultrarrápidos que solo parecen ser registrables por los lenguajes algorítmicos. Dicho de otra manera, al estar provisto de velocidad propia, el cine permite pensar los límites de un ritmo específico que son tanto temporales como espaciales: límite de velocidad en cuanto tiempo, límite de espacialidad en cuanto viaje. Extender el horizonte de visión para pensar los objetos de estudio doctoral agrega a los problemas velocidad y su correlato: lentitud, contingencia, angustia y complejidad, condimentos sin los cuales no valdría la pena intentar el análisis. Hay que tener tiempo para poder pensar.

$\mathrm{Al}$ ampliar y recomponer su campo de visión, el cine muestra la desnaturalización de lo que creemos ver. Se trata entonces de un instrumento creativo que ayuda a investigar esa relación compleja entre la imagen y el tiempo de la que habla Deleuze $^{8}$. El cine escoge sus temas de la cultura vigente y en este accionar nos actualiza, no en el sentido de estar al día, como lo advierte críticamente Antonio Muñoz Molina, sino en la exigencia de hacernos contemporáneos. Es evidente para los propósitos de este trabajo que con el cine salimos del aula, salimos del aprendizaje e incursiona-

8 Ver aquí Gilles Deleuze (1987), La imagen-tiempo. Barcelona: Paidós. mos en otros mundos y modos que interrogan los lugares comunes, por ejemplo: la voz del maestro puede ser el protagonista, la posibilidad de introducir lo absurdo en lo cotidiano, unas existencias colocadas en poéticas del gesto, los auténticos malvados pueden ser los niños, la reinvención del saber y su movimiento, la enseñanza como acción romántica y acaso sublime, la escuela que diluye sus muros al dejar entrar el afuera, entre muchas otras.

\section{Relaciones entre cine y educación}

En las últimas décadas, los trabajos que plantean la relación del cine con la educación han pasado de enfoques bastante procedimentales: el cine como recurso educativo, las películas como herramientas didácticas a conexiones más experimentales e ingeniosas: la relación del cine con la educación social, las representaciones que el cine hace de los sujetos y de la escuela, la pedagogía masiva que el cine ejercita, el cine como pan-arte ${ }^{9}$, la enseñanza del cine y el cine en la enseñanza. Nuestro tiempo parece signar lo educativo por fuera de cualquier frontera y en esta amplitud la red audiovisual prolifera como campo que se abre a nuevas relaciones, inéditas y productivas.

9 Aludimos aquí a los trabajos de Susan Sontag para quien el cine "puede utilizar, incorporar, engullir virtualmente, cualquier otro arte: novela, poesía, teatro, pintura, escultura, danza, música, arquitectura" (Sontag, 2007a, p. 314). 
Investigaciones como las de Inés Dussel y María Silvia Serra en Argentina muestran que es posible relacionar cine y discurso pedagógico, es decir, encontrar puntos de contacto y zonas de fricción entre cine y escuela cuando son examinados históricamente. Advierte Dussel en aquella introducción que "colocar juntos a la escuela y al cine como parte de los intentos de modernización de la cultura y la sociedad en los comienzos del siglo XX" significa que "aunque la escuela sea más vieja que el cine y hoy cueste verle algún parentesco con él, si se le mira históricamente no hay duda de que hay que ubicarla dentro de las series de las tecnologías que buscaron producir nuevos sujetos" (Serra, 2011, p. 10). Argumento análogo al tejido por Jacques Rancière al insinuar las posibilidades teóricas y metodológicas de vincular historia y cine ${ }^{10}$.

Ya insinuábamos el cine como lugar de experimentación que permite el juego, la composición, la superposición de planos, la comprensión de la discontinuidad, la variación del tiempo y del espacio; estos y otros elementos son articulables a las problemáticas académicas propias de la investigación educativa. Man Ray, el fotógrafo que hizo suya una versión del dadaísmo norteamericano, dijo alguna vez que los peores filmes que pudo ver, aquellos que le hacían dormir profundamente, contenían siempre cinco minutos maravillosos, en tanto que los mejores, los más celebrados, contaban solamente con cinco minutos que valían la pena. Esa brevedad, esa exigencia de síntesis, constituye por supuesto su poética, lo que habría que sacar a la superficie.

Dice Tarkovski en Esculpir en el tiempo que con el cine: "Por primera vez en la historia de las artes el hombre encontró el medio para imprimir el tiempo y, simultáneamente, la posibilidad de reproducir ese tiempo en la pantalla tantas veces como lo desease", luego agregaría que "en el cine, la puesta en escena está destinada a emocionarnos, a afectarnos vitalmente por la probidad de las acciones que se nos presentan, por la belleza y profundidad de sus imágenes" (Tarkovski, 1991, p. 44). Cine y educación coinciden en el lugar del gesto, en esa proximidad que se muestra y no puede ser completamente afirmada.

10 Dice Jacques Rancière que habría que pensar la importancia del cine para estructurar una historicidad, una relación con el pasado y la relevancia de la historia para configurar una idea de narración y de devenir cinematográfico. Comenta también que "para Godard: el cine es culpable de no haber filmado los campos en su tiempo; es grande por haberlos filmado antes de su tiempo, es culpable de no haber sabido reconocerlos" (Rancière, 2001). 
Habría que reiterar con Benjamin que en el momento en el que la obra de arte reproducida se convierte cada vez más en una obra de arte dispuesta a ser reproducida, la función social del arte queda subvertida, es decir, que en lugar de fundamentarse en el ritual, pasa a fundamentarse en una praxis distinta: a saber, en la política (2008, p. 103). Más que el dominio de la imagen estética, estaríamos en la esfera de lo ético y de lo político, el gesto como memoria histórica con sus ambigüedades e ideologías.

Existen otras coincidencias no menos interesantes entre cine $y$ educación. El cine ha sido aclamado con demasiada frecuencia como el arte democrático, el arte predominante de la sociedad de masas ${ }^{11}$. En la educación habría que llamar la atención sobre aquel ideal democrático que opera como expresión de un conjunto de ilusiones de las que no resulta fácil desprenderse: la igualdad de los niños ante la escuela, que sería equiparable a la igualdad de los hombres ante la ley; la idea de que la mayoría de la población puede aspirar a la movilidad

11 Ver aquí Las técnicas audiovisuales de Celestin Freinet: "La imagen es hoy la forma superior de comunicación. Y contrariamente con lo que ha pasado con la escritura y el libro, que no han logrado sustituir al lenguaje, hoy estamos ante una técnica que tiende a generalizar su supremacía. Ya no se trata solamente de una élite o de una minoría de privilegiados o de especialistas la que ha sido afectada por este hecho, sino de la masa del pueblo y del conjunto de los pueblos, ya que serán países enteros los que pasarán tal vez de una cultura de la palabra a la cultura de la imagen sin pasar por la etapa media de la escritura y del libro" (Freinet, 1974). social en virtud a reglas y prácticas de equidad de oportunidades; las verdades intemporales que nos hacen aspirar a la justicia y al bienestar común, en fin, funciones históricas que conectan educación y democracia. Esta conexión con lo democrático no es solo una alusión ideal, se traduce en prácticas divulgativas de impacto amplio. No existe, sin embargo, ninguna razón para hacer hincapié en un único modelo de cine, democracia o educación.

\section{El cine como campo de visión}

La promesa central del cine no pasa por su simple entretenimiento. Al no remitirse más que a sí mismo, al no representar necesariamente un algo que lo constituya y lo legitime, más allá de su propia velocidad visual, el cine pide hoy más que nunca ser abordado de otra manera, pensarlo de otro modo y relacionarlo con esas otras pasiones que hacer parte de nuestra existencia. Si bien los discursos en torno suyo parecen declararse insuficientes, "lo que los cineastas contemporáneos muestran con frecuencia cada vez mayor es el mismo proceso de ver, suministrando justificaciones o pruebas a favor de varias maneras distintas de ver el mismo elemento, que el espectador puede ejercitar simultánea o sucesivamente" (Sontag, 2007b, p. 171), interesa entonces el cine como arte, como campo de visión, como lenguaje, como documento y como testimonio de nuestro tiempo. 
Encadenar estas posibilidades pasa siempre por la percepción. En un famoso ensayo de 1935 titulado La obra de arte en la época de su reproductividad técnica, el autor señala que "el modo y la manera en que la percepción sensorial se organiza no solo está condicionado por la naturaleza, sino también por la historia" (Benjamín, 2008, p. 98). Lo contemporáneo del cine supone modificaciones en los modos de percepción cuyos efectos son útiles al momento de ordenar un campo de visión ${ }^{12}$ y de interrogación.

Al ser hoy un escenario de nuestra propia representación, el cine juega como un filtro ya ineludible de lectura y lectores, de emisores y espectadores, de miradas explícitas y de miradas furtivas; un escenario no completamente iluminado, capaz de modular penumbras, zonas de sombra y espacios de luz a través de las cuales se anuncian nuestras inquietudes y nuestros desencantos. Imposible no establecer analogías con las prácticas del trabajo investigativo. Volvemos a Sontang: "Lo que se acostumbra calificar con condescendencia como la artificialidad exageradamente exquisita del arte contemporáneo, que conduce a una especie de autofagia, se puede definir, con tono menos peyorativo, como la liberación de nuevas energías del pensamiento y la sensibilidad" (2007b, p. 171). Un espacio y un tiempo de adscripción vital en el que se ejerce el poder híbrido y polimorfo de enunciar con palabras y de mostrar un campo de visibilidad irreductible al lenguaje.

Sabemos que la proliferación de la comunicación eficaz suprime la palabra y todo aquello a lo que habría que prestar atención. El lenguaje lleva la marca del que habla por que solo allí podemos reconocer la propia voz, que implica además el gesto, la pasión que atraviesa el cuerpo. La voz, para decirlo con Walter Benjamín, no es otra cosa que la marca de la subjetividad en el lenguaje. Las diversas formas del lenguaje están siempre ligadas a la experiencia del que habla y claro, a la experiencia del que escucha, a los avatares del encuentro y, por supuesto, a nosotros con nuestras preocupaciones y vacilaciones. Importa entonces hablar con el lenguaje del cine, y entiéndase este hablar como una práctica que usa el lenguaje verbal, gestual, escrito, y no únicamente la simple comunicación para dar cuen-

12 Dice Alexander Arnoux que "el cine no ha captado todavía su verdadero sentido, sus posibilidades reales. Estas consisten en su capacidad singular para expresar, con medios naturales y con una fuerza de convicción incomparable, lo quimérico, lo maravilloso, lo sobrenatural" (1964, p. 28). 
ta de la pedagogía, la educación, la escuela, el maestro, la enseñanza y otros objetos propios de nuestras investigaciones.

La perspectiva de abordaje de la relación cine, investigación y educación debe ser lo múltiple, desde lo más cercano a nuestros intereses, desde las implicaciones éticas, desde la capacidad de activar la metáfora, en fin, usar la relación como un pretexto que nos abre a la reflexión, al debate, a la intensificación de la sensibilidad y también, claro está, a la risa y el buen humor que nunca puede faltar en lo que hacemos. Quizá sea cierto, como lo pensaba Godard, que podemos elegir entre la ética y la estética, pero es igualmente cierto que sin importar la opción elegida encontremos la otra al final del camino.

Tanto lo múltiple como el campo de visión que se intenta entretejer con estas relaciones brindan un lugar a la crítica. Podríamos aludir a directores de cine como ejercitantes de formas específicas de lectura y de crítica. Jean-Luc Godard, por ejemplo, ha creado un cine que dialoga y hace intercambio con la novela; Ingmar Bergman hace del cine el refugio natural para aquellos que desconfían del lenguaje; Robert Bresson nos ha heredado un cine intelectualizado, excesivamente frío y geométrico; Abbas Kiarostami apuesta por una mirada más limpia frente a todo tipo de convenciones. La crítica de estos directores funciona como una forma superior de lec- tura, más alerta, más activa, capaz justamente de separar y discernir unidades comunes.

\section{Blow-Up ${ }^{13}$ y Las babas del diablo}

La historia de un fotógrafo (delimitado como personaje) parece ser el primer elemento en común de las dos obras. Cortázar sitúa a Roberto Michel, francochileno, traductor y fotógrafo en un París existencialista, en tanto Antonioni compone un personaje que es simplemente un fotógrafo de modas que vive en Londres y del que sabemos por sus notas que se Ilama Thomas. Si el personaje central del cuento y de la película es un fotógrafo, habría que detenerse a pensar la función que cumple en ambos formatos la imagen.

Luego de invocar a Treinisch: "Hay que sacar provecho del poder del ojo humano", Virilio advierte en la velocidad de la liberación que: "Si hasta hace poco había un artesanado de la visión, un "arte de ver", nos encontramos hoy en presencia de una "empresa de las apariencias sensibles", que bien podría ser la forma de una perniciosa industriali-

\footnotetext{
3 Título original: Blow-Up. País: Inglaterra e Italia. Año: 1966. Duración: 110 minutos. Director: Michelangelo Antonioni. Guión: Michelangelo Antonioni, Tonino Guerra con la colaboración de Edward Bond. Fotografía: Carlo di Palma Montaje: Frank Clarke. Vestuario: Jocelyn Richards. Música: Herbert Hancock. Producción Carlo Ponti para MGM. Intérpretes: David Hemmings (Thomas), Vanessa Redgrave (Jane), Sarah Miles (Patricia), Peter Bowles (Ron), John Castle (el pintor), Jane Birkin, Gillian Hills, Julian Chagrin, Claude Chagrin, Verushka von Lehndorff.
} 
zación de la visión" (Virilio, 1997, p. 119). ¿Qué es lo que vemos? ¿Cuál es nuestro campo de visión en lo que educación y pedagogía respecta? ¿No será que pasamos y repasamos formas y modelos que no son más que reiteración, encubrimiento y superficialidad?

La reflexión sobre la imagen es en nuestras investigaciones y en Blow-Up uno de los puntos más importantes de conceptualización. Al leer Las babas del diablo, el narrador hace explícitos pensamientos que bien puede compartir el director de la película: "De todas maneras cuando se anda con la cámara hay como el deber de estar atento, de no perder ese brusco y delicioso rebote de un rayo de sol en una vieja piedra... Michel sabía que el fotógrafo opera siempre como una permutación de su manera personal de ver el mundo por otra que la cámara le impone insidiosa" (Cortázar, 1997, p. 216).

En efecto: ¿Cuál es la verdadera infancia? ¿Cuáles son las huellas y las heridas del maestro? De la respuesta a este tipo de interrogantes dependen un gran número de consecuencias prácticas en la vida cotidiana. Si no hay ya fotografía en el sentido de sus inventores, sino simplemente una detención en la imagen, estamos en presencia de la automatización de la percepción del mundo. "La visión ya no es la posibilidad de ver, sino la imposibilidad de no ver" (Gary Hill). No importa si jugamos al Blow-Up.

En el lenguaje técnico de la fotografía, blow-up es la definición de la máxima ampliación de una imagen, esto resulta ser una de las formas más insistentes e incisivas de la exploración sobre el tiempo detenido, el tiempo muerto. No en vano pensaba Antonioni que:

Cuando se utilizan ampliadoras pueden verse cosas que probablemente el ojo desnudo no sería capaz de captar... El fotógrafo de Blow-Up, que no es un filósofo, tampoco un investigador, quiere ver las cosas más de cerca. Pero lo que sucede es que, al ampliarlas demasiado, el objeto se desintegra y desaparece" (Antonioni, 1970).

Lo mismo ocurre con la proliferación de estudios sobre competencias, calidad o cognición, focalizan tanto su objeto que terminan por hacer desaparecer lo sustancial, quedando en posesión de un residuo: la mente o el aprendizaje, por solo poner un ejemplo. 
El fotógrafo de Antonioni halla en una de las imágenes que captura con su cámara en el Maryon Park el detalle de un cadáver, que más allá de interpelarnos sobre la vida y la muerte como hechos concretos, nos empuja a repensar lo que es real y aquello que no lo es.

\begin{abstract}
Al ser incesante el desfile óptico se torna difícil, y hasta imposible, creer en la estabilidad de lo real, en la fijación de un visible que no cesa de huir, cediendo el espacio de lo inmueble repentinamente a la inestabilidad de una imagen pública que se ha vuelto omnipresente (Virilio, 1997, p. 121).
\end{abstract}

El eco de esta reflexión es similar al relato cortazariano al delatar un pensamiento de Roberto Michel:

Creo que sé mirar, si es que algo sé, y que todo mirar resuma falsedad, porque es lo que nos arroja más afuera de nosotros mismos... De todas maneras, si de antemano se prevé la probable falsedad, mirar se vuelve posible; basta quizá elegir bien entre el mirar y lo mirado, desnudar a las cosas de tanta ropa ajena. Y, claro, todo esto es más bien difícil (Cortázar, 1997, p. 217).
El carácter ambiguo de la imagen como instrumento del conocimiento de la realidad es lo se juzga ${ }^{14}$. El protagonista es testigo de un crimen que al ojo desnudo no fue capaz de ver y cuando procura elucidarse a través de la observación de las imágenes que registró con su cámara de fotos no encuentra una respuesta cabal: se eteriza, se le vuelve una mancha. Lo fundamental ocurre en ese combate que el protagonista establece con el objetivo fotográfico y la disección de las imágenes a la que se dedica de ampliación en ampliación. No es simple analogía, pero los objetivos del investigador operan de la misma forma. Pensemos en las limitaciones a las que somete la complejidad de la enseñanza, a no ser que esta sea una mera instrucción, con el objetivo de obtener aprendizajes eficientes, pertinentes y significativos.

Los conceptos filosóficos que pueden ser expuestos desde Blow-Up

14 Aludimos aquí a la conversación del fotógrafo con el pintor:

-Ese debe tener cinco o seis años. No dicen nada cuando los pinto. Una real confusión. Con el tiempo suelo encontrar algo que vale. Como esa pierna. Luego adquiere forma y tiene sentido. Como una pista en una novela policial. No me preguntes lo que es. No sé aún.

- ¿Me lo vendes? -No.

- ¿Me lo regalas? -No.

-iCondenado! No quiere venderme ninguno de sus mamarrachos. Vendré una noche y se lo robaré.

No podemos olvidar a Virilio, quien nos advertía que "Cézanne y los impresionistas no habrían existido sin la aparición de la fotografía, es decir, sin la negación de un modo de representación del mundo que aquella había acaparado. El realismo, el objetivismo, la objetividad fotográfica llevan a los grandes pintores a divergir" (Virilio, 1999, p. 26). 
permanecen en un segundo plano mientras se camufla la pregunta detrás de una cuestión que simplemente pretende ser un catalizador de la historia, el tejido de dudas que se construyen desde el principio genera una revolución sobre la mirada, apostando por aquello que no se ve sobre el ejercicio de ver. Antes de cerrar estos comentarios, volvamos al diálogo en el parque y a la escena final, pero esta vez recordando el consejo de Barthes: "Su héroe favorito es el que mira. Es peligroso, ya que al observar, al mirar más tiempo del necesario, se desequilibra el orden establecido, en tanto que, normalmente, el tiempo exacto de una mirada es algo que dicta la sociedad".

Thomas intenta irse, pero lo alcanza Jane:

-¿Qué está haciendo? No, no haga eso. No puede fotografiar a la gente así.

-¿Quién dice que no? Es mi trabajo. Algunos son toreros, otros son políticos, yo soy fotógrafo.

-Es un lugar público. Tenemos derecho a estar en paz.

-No es mi culpa que no haya paz. Muchos me pagarían para que los fotografiara.

-Yo le pago.

-Mi precio es elevado. En el rollo hay fotos que quiero.

$-i$ Y entonces?

-Yo le mando las fotos.

- ¡No! ¡Las quiero ahora!

-¡No! ¿Por qué tanta prisa? No arruine todo. Recién nos conocemos.

-No nos conocemos. Jamás lo he visto.

$Y$ aquella secuencia final de Blow-Up que resulta fundamental para el curso del filme y su temática. Es una de las más célebres y seguramente una de la que más fuerza guarda: el fotógrafo asiste a un partido de tenis protagonizado por un grupo de hippies mimos de caras pintadas de blanco. Jugadoras y público asistente siguen atentamente las idas y venidas de una pelota invisible entre uno y otro lado del campo de tenis. La secuencia es larga, se fija en los gestos de los jugadores y en el ritmo de los movimientos de cabeza de los espectadores. Cuando la vista de todos se dirige fuera del campo, indicando que la pelota ha caído fuera de su alcance, el fotógrafo la recoge y se la devuelve para que el juego prosiga. La puesta en escena es perfecta, la es- 
cena es muda a excepción del ruido de la pelota, una pelota invisible.

El juego entre la verdad y la fantasía, lo que fue y lo que pudo haber sido, lo que sucedió de verdad o lo que tal vez no sucedió nunca; ese extraño camino por el que deambula el protagonista durante 24 horas, de un amanecer a otro, enmarcado en la fantasmagórica presencia de un grupo de extrañas gentes de rostros pintados de blanco, será uno de los mensajes más profundos que el cine nos haya dado. Ese juego final donde el protagonista acaba por intervenir para, después, disolverse y dejarnos la amargura de no saber si realmente hemos llegado a conocer o ha sido tan sólo un espejismo.

\section{Ver, preguntar, insinuar y no concluir}

Dice Paul Virilio que la gran ruptura del siglo XIX, además de la revolución de los transportes y de la industria, es la llegada de una estética de la desaparición. Sensibilidad que alude al papel que van a cumplir la fotografía y el cine en nuestro campo de percepción. En oposición a las formas presenciales de la pintura y la escultura, que dependen enteramente de sus sustratos, el mármol o el lienzo, la fotografía y el cine revolucionan el campo visual al incorporar velocidad y movimiento a nuestra visión del mundo. Desde entonces habría que decir con Virilio que somos hombres "del percepto tanto como del concepto" (Virilio, 1999, p. 24).
Estas derivaciones en el análisis son relevantes cuando nos disponemos a hacer investigación educativa y pedagógica. Al pasar por la invención de la fotografía y el cine, los fenómenos existen en tanto desaparecen, hablamos hoy de la dilución del maestro, del abandono de la formación, de la pérdida de la experiencia. Podemos decir también que si no se diluyen se reconfiguran, por ejemplo, las infancias, las reformas, la modernización, los tiempos, los espacios, la ubicuidad como fenómeno posible. Estos ejercicios de interrogación, crisis y enrarecimiento próximos a la estética del movimiento inauguran un lugar estratégico cuyas consecuencias serán otra política, otra técnica ${ }^{15}$, otra crítica, también, por supuesto, otra investigación.

En la misma perspectiva, señala Virilio que "la velocidad proporciona qué ver". "Llegar más rápido al punto de destino significa por supuesto otro modo de mirar y pensar". Ver, antaño con la fotografía y el cine, y concebir hoy día con la electrónica, la calculadora y el ordenador, representa un cambio gnoseológico; es más, "el espacio público se convierte en una imagen pública a través de la fotografía, el cinematógrafo y la televisión" (Virilio, 1999, p. 24).

La lucidez de esta sospecha introduce en el análisis educativo derivaciones que no podemos obviar.

\footnotetext{
15 La utilización de la radio y del cine por parte de Goebbels, ministro de Comunicaciones de Hitler, es prueba de ello.
} 
Primero, si la velocidad cambia el tiempo y el espacio de percepción, habría que averiguar cómo los nuevos tiempos y los nuevos espacios transforman la forma de educar en relación con lo que se fundó hace más de dos siglos. Incluso, la pregunta sería: ¿Es posible educar hoy?

Segundo, si el tiempo ya no es local, sino mundial, qué ocurre con las formas de relacionarnos con los tiempos locales en términos de subjetivación, modernización y gestión del saber.

Tercero, si la velocidad da un ritmo a la sociedad en que vivimos el manejo y la economía de la velocidad es un tema político y educativo de primer orden, una amenaza a la vida misma. La velocidad no es un fenómeno, sino una relación entre los fenómenos, lo que explicaría el auge de la cibernética como relación entre los conocimientos. La ubicuidad, la instantaneidad y la inmediatez son atributos de la velocidad de hoy que interrogan la escuela, al maestro y a la práctica misma.

Cuarto, la forma no tiene velocidad, la fuerza da a la forma dirección y velocidad, es decir, retención, freno, aceleración; la educación pasa por ahí, por el aprendizaje, por su velocidad, que se traduce en mayor eficacia, mayor eficiencia y otros controles cotejables desde la evaluación. No se des-inventa el aprendizaje, hay que superarlo con otro concepto.

Quinto, cuando la educación se extiende a todos, se promueve como en la ciudad una catástrofe, no se trata de un fatalismo. La enseñanza exige con-tacto, pero la educación de hoy en espacios abiertos puede hacerse incluso sin tacto. La educación nos desborda, es decir, que estamos en el borde y en su desborde.

Sexto, como la velocidad elimina el trayecto, podemos pensar al maestro como un trayecto que en su trayectoria vacila, incita, retorna, tiembla; si va muy rápido se diluye, se queda sin lugar, se queda en el plano virtual. La velocidad afecta su corporeidad, lo vuelve espectro, un extraño tragaluz.

Séptimo, la velocidad nos estrecha porque en su aceleración perdemos la dimensión compleja del mundo y del conocimiento. Habría también una pérdida del encanto, si hoy se encuentra de todo, desaparece la ilusión, si Google lo sabe todo, el mundo es más estrecho que nunca. No se trata de ser anacrónico, simplemente exhortamos a la crítica, como lo hizo el impresionismo con la fotografía. 
Octavo, ya no parece haber lentitud, contemplación, sorpresa. Como en la hechura de una casa, ya está todo acabado en los acabados. Hoy nos movemos en las políticas educativas de la velocidad.

Finalmente, nos queda advertir sobre un gesto que parece común a algunos maestros y a algunos fotógrafos. Así como la enseñanza pasa por tener tiempo, por las pausas propias del contemplar, del hablar y del pensar, lo que significa que podría ser vista como un modo de resistencia al vértigo de la velocidad; existen también fotógrafos como Gabriel Basilico que construye, poco a poco, un "instrumental" personal, una mirada y un lenguaje que lo llevan a reiterar su repertorio, para ello utiliza una cámara antigua, una cámara que le impone un procedimiento lento y poco contemporáneo, pero que le permite adquirir conciencia del espacio, o mejor, cuya consecuencia ha sido una percepción del espacio inédita, sin duda ligada a la mirada, pero también al caminar, al movimiento físico, a la búsqueda de un punto desde el cual obturar.

Durante mucho tiempo, las ideas que buscaban revolucionar el arte pasaban por exigencias de alto refinamiento, en su defecto, estos procedimientos, de la enseñanza y de la fotografía, resultan extraños, precisamente porque intentan observar y pensar desde el afuera.

\section{Referencias}

Antonioni, M. (1970). El grito, las amigas, la aventura, BlowUp. Madrid: Alianza.

Arnoux, A. (1964). Cinema. París: La Nouvelle Edition.

Basilico, G. (2008). Arquitecturas, ciudades, visiones. Reflexiones sobre la fotografía. Madrid: La Fábrica.

Benjamin, W. (2008). Sobre la fotografía. Valencia: Pre-Textos.

Cortázar, Julio (1997) Las babas del diablo. Cuentos completos. Madrid: Alfaguara.

Cortázar, J. (2009). Papeles inesperados. México: Alfaguara.

Deleuze, G. (1987). La imagen-tiempo: Estudios sobre el cine 1. Barcelona: Paidós.

Foucault, M. (1995). Vigilar y castigar. El nacimiento de la prisión. México: Siglo XXI.

Freinet, C. (1974). Las técnicas audiovisuales. Barcelona: Laia.

García Márquez, G. (2007). Cien años de soledad. Bogotá: Santillana.

Larrosa, J. (1998). Bildung y nihilismo. Notas sobre Falso movimiento, de Peter Handke y Win Wenders. Revista Educación y Pedagogía, (X)22, pp. 61-77.

Lévy, P. (1999). ¿Qué es lo virtual? Barcelona: Paidós.

Mancini, M. \& Perella, G. (1987). Michelangelo Antonioni. Arquitectura de la visión. Roma: Alef-Finmedia Catania. 
Nietzsche, F. (2001). Todos los aforismos. Buenos Aires: Ediciones Leviatán.

Quintana, A. (2011). Después del cine. Imagen y realidad en la era digital. Barcelona: Acantilado.

Rancière, J. (2001). La fable cinématographique. París: Seuil.

Said, E. (1996). Representaciones del intelectual. Barcelona: Paidós.

Serra, M. (2011). Cine, escuela y discurso pedagógico: Articulaciones, inclusiones y objeciones en el siglo XX en Argentina. Buenos Aires: Teseo.

Skliar, C. (2011). Lo dicho, lo escrito, lo ignorado. Ensayos mínimos entre lo educativo, lo filosófico y lo literario. Buenos Aires: Miño y Dávila.

Sontag, S. (2007a). Contra la interpretación y otros ensayos. Barcelona: Debolsillo.

Sontag, S. (2007b). Estilos radicales. Barcelona: Debolsillo.

Tarkovski, A. (1991). Esculpir en el tiempo. Reflexiones sobre el arte, la estética y la poética del cine. Madrid: Ediciones Rialp.

Virilio, P. (1999). El cibermundo, la política de lo peor. Madrid: Cátedra.

Virilio, P. (1997). La velocidad de liberación. Buenos Aires: Manantial. 